\title{
MRS Embraces Soft Materials
}

One of the great strengths of the Materials Research Society's meetings has been the ability to program quickly and incisively in emerging areas of interdisciplinary materials research. This is particularly true when the area does not easily find a natural home in a more disciplineoriented Society. For example, MRS was founded in part by unmet needs for active programming on interdisciplinary topics for electronic and optoelectronic applications. We have witnessed this area and many others grow into high quality, recurring symposia. Although MRS must nurture the evolution of such areas, it must also seek out other emerging areas of an interdisciplinary nature that involves materials research. One such area is that of soft materials, which will probably remain at the forefront of interdisciplinary materials research for decades.

What is a soft material? Like many terms in our field, the definition depends on the definer. With a structural materials background, I think of a weakly bonded, probably organic-based material with low modulus, yield strength, and hardness, hence also low toughness, even if also characterized by appreciable plasticity. However, such a definition is like the proverbial blind man trying to describe an elephant by having touched only the tail. MRS needs to embrace the whole animal.

Even if defining soft materials is a trying exercise, it is easy to identify topics that must fit within any unified description. A glance at the 1999 MRS Spring Meeting program suggests several: membranes; electro- and magneto-rheological

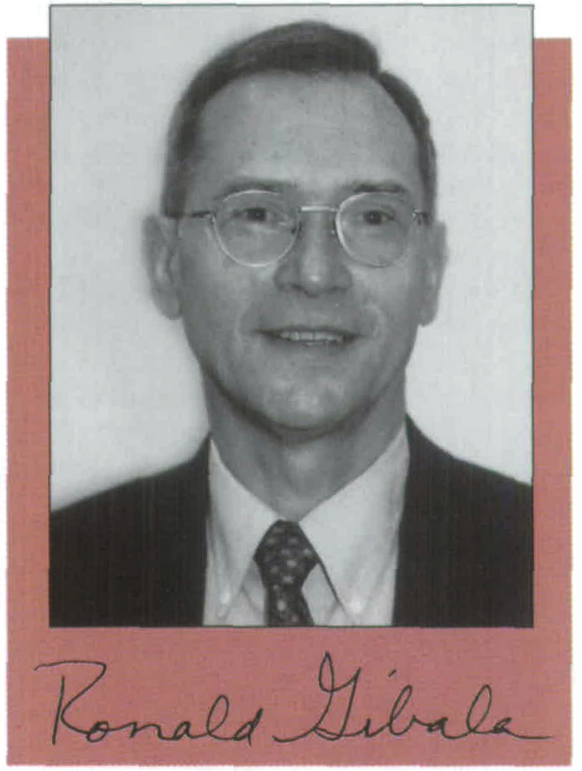

fluids; gels and colloidal systems; tissue engineering; and cellular, extracellular, and supramolecular structures. Various issues of MRS Bulletin have theme topics or technical articles on soft materials topics; for example, the October 1999 issue will feature the materials science of the cell. The recent report of the National Science Foundation/Department of Energy Workshop on Interdisciplinary Macromolecular Science and Engineering gives a substantial, but hardly comprehensive, listing of topical areas of soft materials from which MRS should develop symposia. Imagine future symposia on the materials science of human repair, engineered materials from nanobricks, new plastics from plants, and cell/computer interfaces and junctions.

The MRS Executive Committee has convened a task force to examine the role of soft materials as an element of the MRS programming future. The task force will attempt to answer questions such as: What all does the area of soft materials entail? What critical areas are best served by MRS programming? What are the elements of a strategic plan for implementation of enhanced MRS programming in soft materials? How might this be done in conjunction with other Societies?

Either through expansion of the Program Committee or other possible committee reorganizations, we hope to follow similar approaches for other key areas, such as microelectromechanical systems and micromachines, new instrumentation developments, and a host of technological problems for which interdisciplinary materials issues are of paramount importance.

Please share with me your ideas on soft materials or any area of interdisciplinary materials research that you feel needs MRS programming as a means of advancing knowledge. In parallel, and for possibly more rapid action, propose your ideas to the Chairs for future Spring and Fall Meetings or to the MRS Bulletin editor.

RON GIBALA

1999 MRS President 925-294-4751* 925-294-3410 (fax $)^{*}$ rgibala@sandia.gov (e-mail)* *Through July 31, 1999

\section{MRS Bulletin Editor \\ Betsy Fleischer \\ MRS Bulletin \\ Materials Research Society \\ 506 Keystone Drive \\ Warrendale, PA 15086-7573, \\ USA \\ 724-779-3004 ext. 521 \\ Fax: 724-779-8313 \\ E-mail: fleischer@mrs.org \\ MIRS}

Ellen D. Williams University of Maryland 301-405-6156

Fax: 301-314-9465 williams@surface.umd.edu

2000 Spring Meeting Anna C. Balazs

University of Pittsburgh 412-648-9250

Fax: 412-624-9639

balazs@vms.cis.pitt.edu

Robert Q. Hwang

Sandia National Laboratories 510-294-1570

Fax: 510-294-3231

rqhwang@ca.sandia.gov
Kevin S. Jones University of Florida 352-392-9872 Fax: 352-392-8381 kjones@eng.ufl.edu

Frances M. Ross IBM T.J. Watson Research Center

914-945-1022

Fax: 914-945-2141

fmross@watson.ibm.com

2000 Fall Meeting

Sungo Jin

Lucent Technologies/Bell

Labs Innovations

908-582-4076

Fax: 908-582-4868

jin@bell-labs.com
Tony Mikos Rice University

713-285-5355

Fax: $713-285-5353$

mikos@rice.edu

David Srolovitz University of Michigan 313-936-1740

Fax: $313-763-4788$ srol@umich.edu

Bernd Stritzker University of Augsburg 49-821-5983400

Fax: 49-821-5983425 stritzker@physik. uni-augsburg.de 